\title{
Design and Development of Solar Hybrid Bicycle
}

\author{
Kartik S Mishra*, Shubham V Gadhawe, Dhiraj C Chaudhari, BhupendraVarma and S. B. Barve \\ Department of Mechanical Engineering, MIT College of Engineering, Kothrud, Pune, India
}

Accepted 02 March 2016, Available online 15 March 2016, Special Issue-4 (March 2016)

\begin{abstract}
Since the fuel prices not only in India but throughout the world is increasing day by day thus there is a tremendous need to search for an alternative to conserve these natural resources. Thus a solar bicycle is an electric vehicle that provides that alternative by harnessing solar energy to charge the battery and thus provide required voltage to run the motor. Since India is blessed with nine months of sunny climate thus concept of solar bicycle is very friendly in India. Hybrid bicycle combines the use of solar energy as well as the dynamo that runs through pedal to charge the battery to run the bicycle. Thus solar hybrid bicycle can become a very vital alternative to the fueled automobile thus its manufacturing is essential.
\end{abstract}

Keywords: Solar energy, Hybrid vehicle

\section{Introduction}

A solar bicycle is a bicycle which runs using the electrical energy of battery to run the hub motor which ultimately runs the bicycle. Solar energy is used to charge the battery. Two or more Photovoltaic cells may be used to harness solar energy to generate voltage to charge the battery. Battery gives the required voltage to the hub motor mounted on the front wheel to run the bicycle.

Solar bicycle are not sold generally in our everyday life but there manufacturing can be increased to prevent environmental pollution. These are primarily used as an practical projects and are also sometimes sponsored by government agencies.

There have been many patents on electrical vehicles in different countries and thus electric vehicles are not a very new concept. Utilizing solar energy to charge the battery and combining this concept with the concept of electricity generation pedaling is a new concept and there have been very less research in this regard.

Solar bicycle use photovoltaic cells that convert solar energy into required voltage to charge the battery. There are two types of solar panels that are generally used that is polycrystalline panels and microcrystalline solar panels. The polycrystalline panels are having less efficiency as compared to microcrystalline panels. Polycrystalline panels have efficiency of approximately $15-20 \%$ while microcrystalline panels have efficiency of $50-60 \%$.

There are different types of batteries used in electric vehicles like lead acid batteries, lithium ion

*Corresponding author: Kartik S Mishra batteries, Nickel cadmium batteries, etc. Different batteries they have their different advantages for different applications. As far as solar bicycles are concerned lead acid and lithium ion batteries are most commonly used. Lead acid batteries have lower cost, higher current carrying capacity but have smaller life and are heavier. While lithium ion batteries have lower weight but have higher cost and there are chances of explosion.

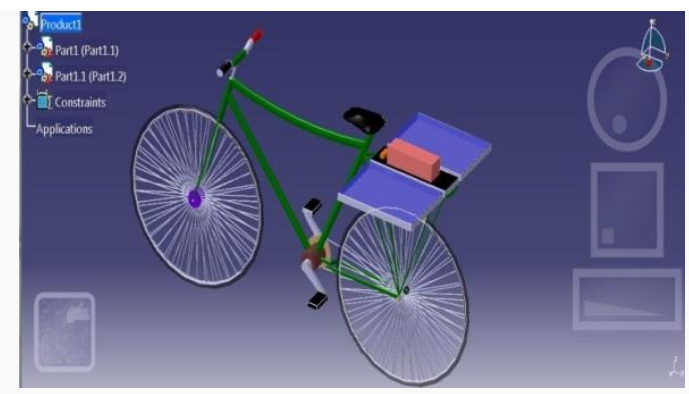

Fig 1: CAD model of solar bicycle

Slowly solar bicyles have gathered attention from all over the world and there have been many projects being done on this topic. The motor used is a permanent magnet Hub motor which will be mounted on the front wheel. While a belt and pulley mechanism will be provided on the rear side of the vehicle to run the dynamo.

\section{Literature Review}

Ajit B. Bachche , N. S. Hanapure: They studied the fuel prices like the petrol is rising steadily day by day. The pollution due to vehicles in heavy traffic cities and urban areas is increasing steadily. To overcome these 
troubles, an effort regarding thisis made to search some other alternative sources of energy for the vehicles. It is not possible to purchase costly vehicles by poor peoples. Keeping this in mind, a search for some way to provide these economically poor people and also to provide a solution for the environmental pollution was in progress. The solar assisted bicycle is driven by DC hub motor mounted in front or rear axle housing \& operated by battery charged using solar energy. The solar panels placed on the carriage will charge the battery \& which in turn drives the hub motor. When the bicycle is idle, the solar panel charges the battery. This arrangement is used to replace the arrangement of petrol engine, the gear box \& the fuel tank in case of two wheeler or a chain sprocket mechanism generally used by common people. Pedal assisted solar hybrid bicycle is a modification of conventional bicycle thus improving its speed as well as it gives the essential comfort to the driver while driving. During their testing they considered a hub motor of 250W 24V capacity.

Henry M. Gannon, 2026 10th St., Boulder, Colo. 80302: Their study was related to a multi-wheeled vehicle not limited to a bicycle. The preferred arrangement consists of a standard conventional bicycle with multi-speed transmission, plus an electrical generating system and a solar charging arrangement. This preferred arrangement is normally powered by a combination of motor and pedaling, coupled such that either or both may provide power at any instance. The electrical system consists of: a DC Hub motor, lead acid batteries, a hand lever operating a throttle means, a throttle means which is used to control the battery switching circuit. They also studied on the mechanism called regenerative braking arrangement utilizes the braking arrangement to generate energy to charge the battery. When the brakes are applied they compress the fluid inside a hydraulic cylinder and when the brakes are removed they release the fluid thus generating energy to charge the battery.

Glenn C. Streif', 25052 Campo Rojo, - Lake Fomst' Calif- 92630: They studied a bicycle which runs on solar energy consists of an solar intensifying collectors it alsoconsists of a two wheeled moped type vehicle supporting a motor generator and a pedal driven crank operating arear wheel drive. This vehicle it further includes a rear portion consisting of a pair of forwardly open air duct having a wind driven generator. It also includes pair of rechargeable batteries are further supported within the rear body portion and array of are supported by vertical collar support in a generally horizontal panel support. The panels are provided with the energy intensifying lens which intensifies the solar rays received from sun.

Solar bicycle is anmodification of conventional bicycle and driven by electrical energy. It can run on any type of either cemented or asphalt road or it can also run on muddy road. Solar bicycle is having very less initial and maintenance cost hence can be used for short distance travel by students, office people. It is suitable for young, aged, handicap people and completes the need of economically poor class society. It can be used throughout the year free of cost. The most importance merit of this bicycle is that it does not consume the necessary fossil fuel which are required in day to day life and thus prevents the environment from pollution and also helps conserve the natural resources.

\section{Methodology of Solar Bicycle}

The solar hybrid bicycle consists of following components - hub motor, solar panel, lead acid battery, motor controller, accelerator, bicycle, dynamo.

\section{A) Hub Motor}

The permanent magnet DC hub motor is a conventional Dc motor. The stator is inside the rotor with the permanent magnets placed inside. The stator is fixed on the axle and the hub will be made to rotate by $\mathrm{AC}$ supplied by the batteries. It generates high torque at low speed, which is highly efficient and which doesn't need sprockets, brackets and drive chains. Thus they are very reliable and have a long life. The main feature of the Brushless DC Machines is that they can be controlled to give wide constant power speed ranges.

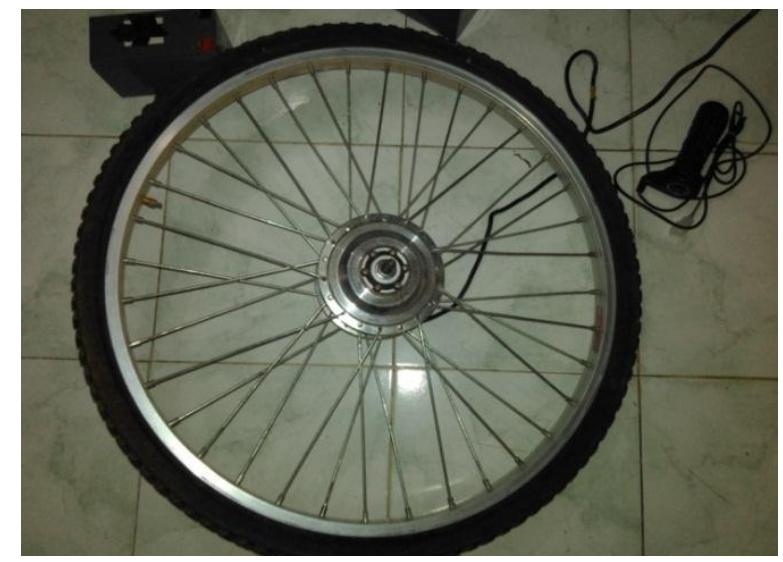

Fig 3: Hub Motor

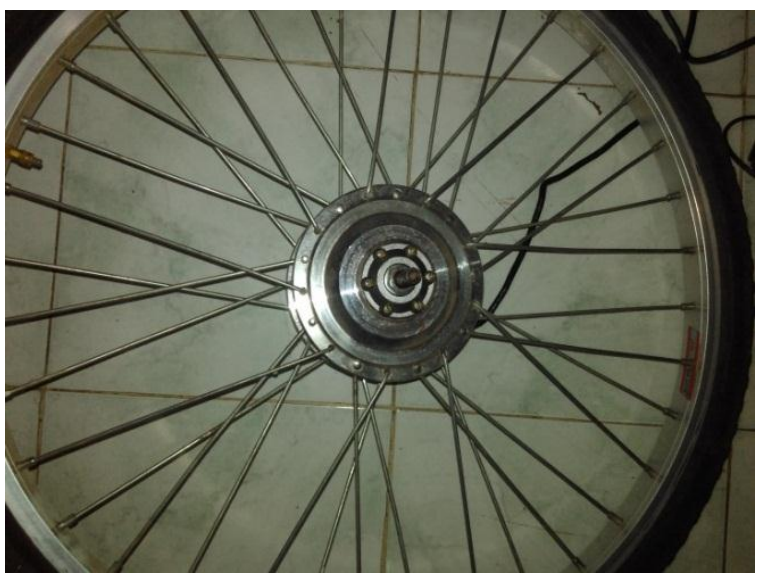

Fig 2: Hub Stator 


\section{B) Solar Panels / Cells}

The solar bicycle is operated by solar energy. The lead acid battery is charged with voltage generated due to solar energy with the help of a photovoltaic cell. Solar cells convert the solar energy directly into electricity using photovoltaic effect. The photovoltaic effect involves conversion of electromagnetic radiation into electrical energy. The photoelectric and photovoltaic effects are related to sunlight, but are different in that electrons are ejected from a material's surface upon exposure to electromagnetic radiation of sufficient energy in photoelectric, and thus the electrons that are generated are transferred to different bands of valence to conduction within the material thus this results into build-up of voltage between two electrodes in photovoltaic. Solar cells are connected electrically and manufactured as a module with a sheet of glass on top to allow light to pass and protect the semiconductor from the weather. To obtain the voltage of $24 \mathrm{~V}$ two panels of $12 \mathrm{~V}$ each are connected in series.

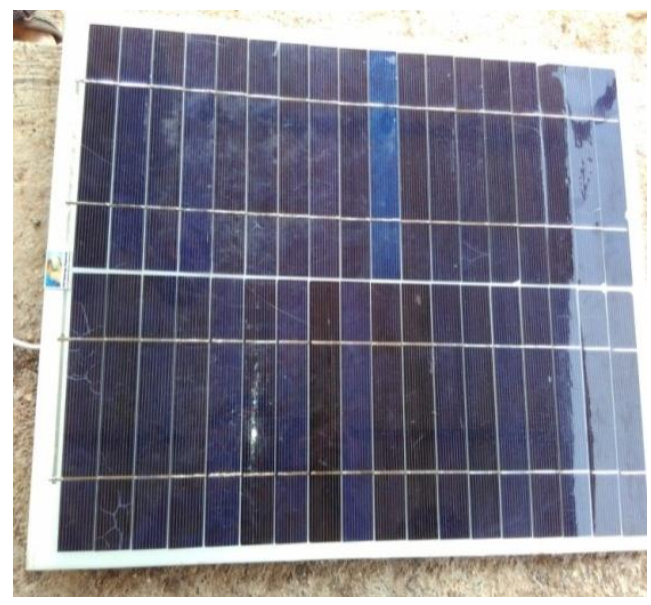

Fig 3. Solar Panel

\section{C) Lead Acid Battery}

Lead acid batteries are very common in our day to day life. It is the most frequently used battery in electronics. Although it has lower energy density than the lithium ion batteries but since is very safe to use lead acid battery with proper precautions taken. It has many advantages like low cost, frequently available, and is also explosion free thus is the most frequently used battery in solar hybrid bicycles. Current supplied from battery it indicates the flow of energy from the battery and is measured in amperes (or Amps). The higher the current rating the slower the battery will discharge. A battery is rated in ampere-hours (abbreviated Ah) and this is called the current rating. This project revolves around charging and discharging energy within a high voltage battery. Thus this project demands for a battery with longer running hours, lighter weight with respect to its high output voltage and higher energy density. Among all the available battery types the lead acid batteries are the most suitable ones to be used in solar hybrid bicycles.

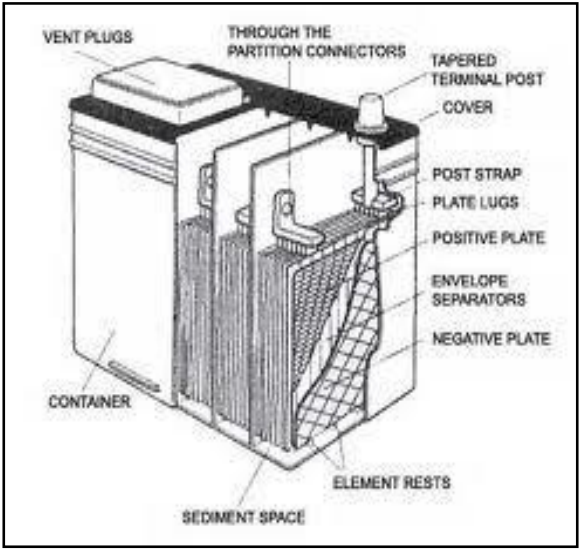

Fig 6: Schematic diagram of Lead Acid Battery

\section{D) Motor Control}

A motor controller is an important element of the solar hybrid bicycle or can be called as the brain of the vehicle. It controls the amount of power supplied to the hub motor and also to the lights and horn if required The motor controller performs the function of conversion of the DC voltage from battery to an alternating voltage with variable amplitude and frequency that drive the hub motor at different speeds. It basically consists of MOSFET transistors and small microprocessor that vary from detecting any malfunctions with the motor hall sensors, the throttle, to protect functions against excessive current and under-voltage.

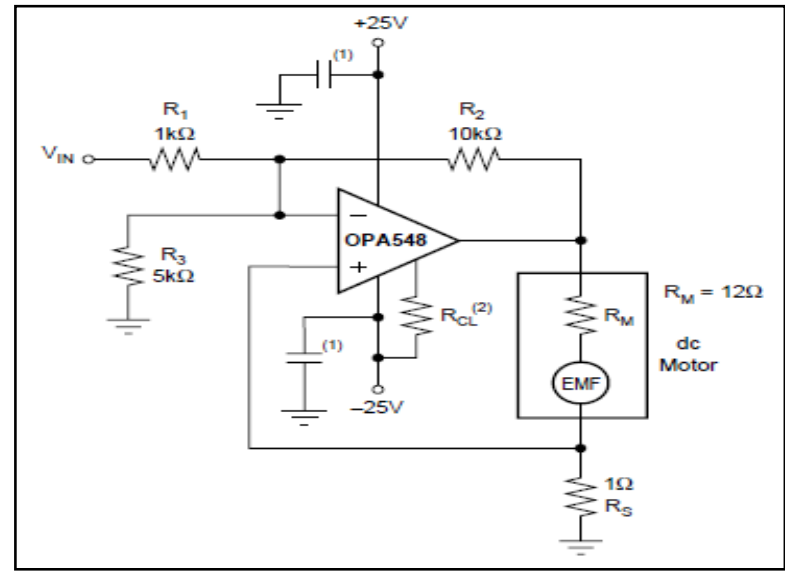

Fig 7: Circuit diagram of Motor Controller

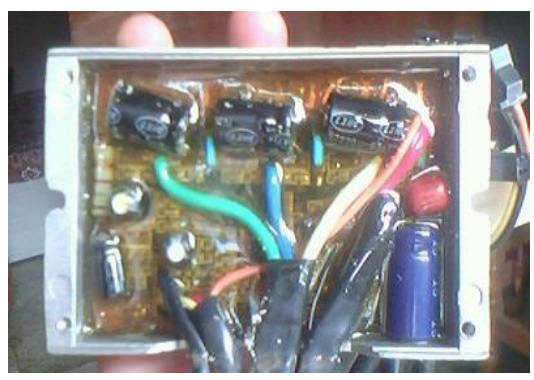

Fig 8: Hub Motor Controller 


\section{Electricity Generation from Pedaling}

A permanent magnet alternator (also called PMA, dynamo or magneto) depends on the magnetic flux generated by a permanent magnet to convert mechanical energy into electrical power. It generates alternating current which charges the battery. In this article the focus is on the typical structure of a permanent magnet structure and also a brief introduction to its working principle. A modern alternator consists of both the moving and stationary coils of wire. In the alternator, however, the moving coil which is also called the rotor, uses current supplied through slip rings to generate a moving field also called flux. Power is extracted from the stationary field coils. The stator combines six coils of copper wire cast in fiberglass resin. It is mounted onto the spine and does not move. The moving parts are the magnetic rotors mounted on the shaft. There are two rotors: the rear one behind the stator and the front one on the outside, which are connected by the long studs passing through a hole in the stator. The blades are mounted on the same studs. They will drive the magnet rotors to rotate and move through the coils. During this process electric energy is produced.

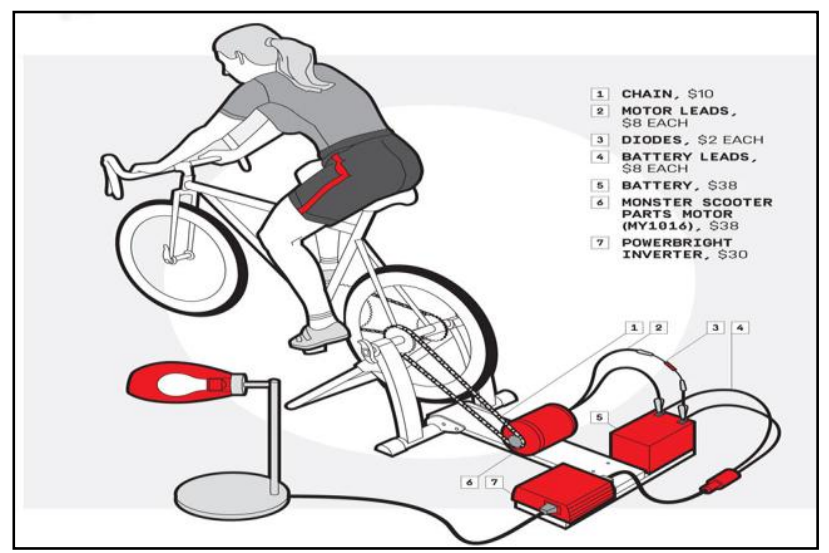

Fig 10: Electricity Generation from Pedaling

\section{Design of Solar Hybrid Bicycle}

\section{Problem statement}

Diameter Of wheel (D) $=60 \mathrm{~cm}$

$\operatorname{Speed}(\mathrm{v})=15 \mathrm{kmph}$

Weight Of Bicycle $=40 \mathrm{~kg}$

Weight Of Rider $=70 \mathrm{~kg}$

\section{Power calculations}

1) Normal reaction $(\mathrm{N})$ on each tyre $=\mathrm{W} / 2=110 / 2=$ $55 \mathrm{~kg}=55 * 9.81=\mathbf{5 3 9 . 5 5} \mathbf{N}$

2) Friction Force (F) acting on each tyre:

For Static Friction, $\mathrm{u}=0.03$

$\mathrm{F}=\mathrm{u}^{*} \mathrm{~N}=0.03 * 539.55=16.1865 \mathrm{~N}$

For Dynamic friction $\mathrm{u}=0.004$

$\mathrm{F}=\mathrm{u}^{*} \mathrm{~N}=0.004 * 539.55=2.1582 \mathrm{~N}$
For static Friction, $\mathrm{T}=\mathrm{F}^{*} \mathrm{R}=16.1865^{*} 0.305=$ $4.9368 \sim 5 \mathrm{Nm}$

For Dynamic Friction, $\mathrm{T}=\mathrm{F} * \mathrm{R}=2.1582 * 0.305=0.658$ $\mathrm{Nm}$

\section{Speed calculations}

$\mathrm{w}=\mathrm{V} / \mathrm{R}=15000 /\left(0.305^{*} 3600\right)=13.67 \mathrm{rad} / \mathrm{sec}$

\section{Power requirement (p)}

A) On plain ground,

For Dynamic Friction, $\mathrm{P}=\mathrm{T}^{*} \mathrm{w}==9 \mathrm{watt}$

For Static Friction, $\mathrm{P}=\mathrm{T}^{*} \mathrm{w}==68.35$ watt

Overall power requirement $=68.35^{*} 2=136.7$ watt

B)On Inclined Surface, $a=2^{\prime}$

total force required to move vehicle

$\mathrm{F}=\mathrm{u}^{*} \mathrm{mg} \mathrm{g}^{*} \cos (\mathrm{a})+\mathrm{mg} \sin (\mathrm{a})$

$\mathrm{F}=70.013 \mathrm{~N}$

Therefor power required $=F^{*} \mathrm{~V}=291.72 \mathrm{~W}$ extra power required $=291.72-136.7=155.02 \mathrm{~W}$

B] Considering dynamic friction

$\mathrm{F}=0.004 * 110 * 9.81 * \cos (2)+110 * 9.81 * \sin (2)$

$\mathrm{F}=41.97 \mathrm{~N}$

Power $(\mathrm{P})=\mathrm{F}^{*} \mathrm{~V}=174.611 \mathrm{~W}$

\section{Battery selection}

Since motor selected is of $24 \mathrm{~V}$ hence battery voltage rating should also be 24 . Therefore we select two batteries of $12 \mathrm{~V}$ and $7.5 \mathrm{Ah}$ in series combination of we get $24 \mathrm{~V}$ and $7.5 \mathrm{Ah}$.

\section{Charging time}

Time required to charge the battery by adapter $12 \mathrm{~V}$ $12 \mathrm{Ah}$

$\mathrm{P}=12 * 12=144 \mathrm{~W}$

$\mathrm{T}=(24 * 12) / 144$

$=2 \mathrm{hrs}$.

By using solar panel

$\mathrm{T}=(24 * 7.5) / 50$

$=3.6 \mathrm{hrs}$

\section{Panel selection}

we use two panels of $25 \mathrm{~W}$ each having dimension $350 \mathrm{~mm} * 550 \mathrm{~mm}$

\section{Motor selection}

Hub motor of $250 \mathrm{~W} 24 \mathrm{~V}$ is selected

\section{Expected results using pedal arrangement}

Using pedal arrangement for charging battery:

Voltage rating for motor $=12-24 \mathrm{~V}$

Rated speed $=1800-3900 \mathrm{rpm}$

Current rating $=14 \mathrm{Amps}$

Power rating $=16-33 \mathrm{HP}$

Lead acid battery $=12 \mathrm{~V}$ battery

Bike wheel to pulley turn ratio is 26 " diameter to 2 " diameter $=1: 13$

15 - 16 miles hours of speed is required to charge a battery of 15 volts

\section{Torque requirement $(t)$}




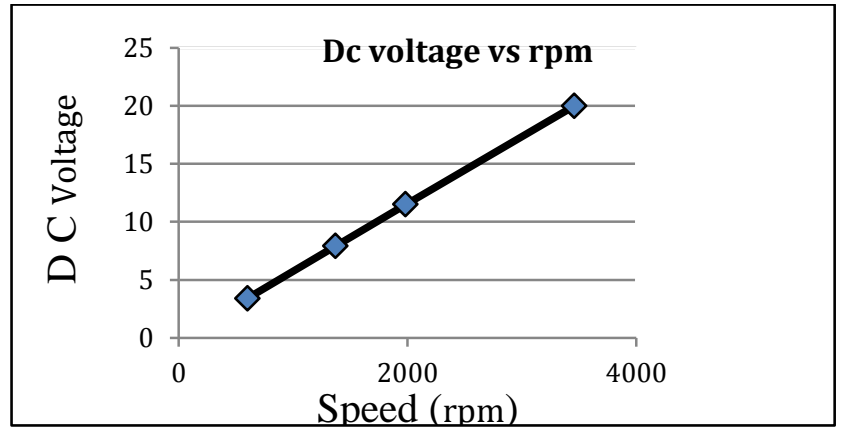

Fig 11: Graph of DC Voltage v/s Speed in RPM

\section{References}

Ajit B. Bachche, N. S. Hanapure 'Design and Development of Solar assisted bicycle' volume 2 , issue 2, December 2012, IJ

HeneryGannon, 'Electric and pedal driven bicycle with solar charging', patent no. 5316101, May 311994.

Glenn C. Streif', 25052 Campo Rojo, - Lake Fomst' Calif92630, 'Solar powered Two - wheeled vehicle with Energy intensifying Solar Collector'

V.B. Bhandari, Design of machine elements, The McGraw. Hill Companies, Second Edition

S.S. Ratan; Theory of Machine, the McGraw. Hill Companies, Second Edition. 